\title{
Continuous Assessment in Software Engineering
}

\author{
Francisco J. García Peñalvo, Miguel A. Conde González, Sergio Bravo Martín
}

Universidad de Salamanca, Facultad de Ciencias,

Plaza de los Caídos s/n, 37008 Salamanca (España)

fgarcia@usal.es, mcondedusal.es, serdusal.es

\begin{abstract}
European convergence towards European Space of Higher Education demands an important innovation process in the academic assessment system. In this sense, continuous assessment presents some advantages which are exposed in this paper due to it introduction as an additional assessment in Software Engineering subject.
\end{abstract}

\section{Introduction}

As result of the convergence towards European Space of Higher Education [1] (from now on ESHE), subjects assessment gets a new approach. In the first place assessment is not limited to check final results, but presents an educational approach based on learning in a way which allows to value if a learner has obtained the knowledge and competences previously established. Secondly, the teacher must assess the assimilation of knowledge and skills development by students, not only at the end of the process but over the period school through regular activities. With this new approach, the evaluation becomes a teaching activity continued, progressive and sometimes evolutionary, in order to adapt to the learning ability of students.

The purpose of this communication is to present the process of continuous assessment in place, since the academic year 2005-2006, in Software Engineering subject at the program of Computer Science Education at the University of Salamanca, as well as share the results to serve as an example and reference in the implementation of evaluation systems that improve the current in the way of adaptation to ESHE.

\section{Teaching Approach of Software Engineering software}

Computer Science Education at the University of Salamanca is organized into two study programs based on an initial three-year cycle (Basic Engineering Degree) and a second cycle of two (Senior Engineering) and a second cycle of two (High-Level Degree). The student makes his first contact with the Software Engineering in the first. This course tries to raise awareness among students on a range of disciplines that are applied regularly and systematically in the work of design and construction software [2].

The subject is taught in the first quarter of the course and consists in 60 hours 4.5 theoretical and 1.5 practical).

Looking at his approach under the new rules of European convergence, the approach of the subject taking equivalence of official credits to European Credit Transfer System (ECTS) is chosen, involving change in teaching methodology. This change in methodology is an 
increase in the work of assimilation and self student, assuming 112.5 hours for these aspects on the theory and 45 hours in the practice. The total number of work hours is 157.5. This number would be between 150 and 180, according to the new rules, depending on whether the each credit has 25 or 30 hours. The work of assimilation is optimal considering the nature of the subject.

In order to understand the different concepts is necessary that the student was capable of performing a job for reflection, assimilation and practice of different underlying concepts of the subject. Encouraging these disciplines, and considering that in most cases students apply every effort to end a learning process whose aim is only pass the subject, it becomes necessary to apply a methodology for continuous assessment.

\section{Assessment Process}

The implementation of continuous assessment in the context of this subject is a major challenge, therefore should be implemented on two large groups with approximately 100 students each one. To do this, the first decision taken was raised as an optional element, which nobody would be forced to follow, and those who follow it and fail would have the opportunity to complete a final exam. The next step was to design a protocol for its development.

To understand the process of continuous assessment is essential to know the official assessment (OA) established in the course. This method consists of two parts, theory and practice, which was evaluated separately and contributing both with $50 \%$ of the final grade:

- Firstly, the theory is assessed through a final exam that consists of two parts: a test and a set of theoretical and practical assumptions. Both should be approved independently.

- Moreover, the practice carried out in working groups, is assessed through a presentation and defence against the professor.

In addition to the traditional evaluation system, students can be optionally chose a continuous assessment (CA), in which attendance and active participation play an important role. This pattern is determined by the following process:

- Related to the test part in the theoretical exam:

- 3 tests will be conducted during the theoretical classes, which shared the contents of the different learning units of the program of the subject. Pass these tests will mean the elimination of part test for the theoretical exam, if student gets a score greater than or equal to 5 in all these tests. Average score only be calculated if in all tests the score is greater than 3 .

- Regarding the part of the set of theoretical and practical assumptions from the exam, student can get points added to the score obtained in this section of the review.

- In practical workshops:

- All groups must hand the exercise defined at the end of the meeting (and printed using any of the modeling tool proposals). If fraud is detected is deducted 1 point.

- The volunteer groups defense the works performed and make reports 
with delivery in 15 days. Both the defense and the report can contribute up 0.5 points each one. If there are no voluntary groups, the teacher will choose randomly a group. In this case both the defense and the report could negatively rate (up to -1), this report would be mandatory.

- Continuously and successful collaboration can contribute up 0.5 points.

- Regarding the delivery of exercises

- May be delivered up to 3 modeling exercises, with instructions obtained from the literature (and unresolved). After its review in tutoring hours might contribute up 0.75 points.

\section{Results and conclusions}

From the academic year 2005-2006, the subject of Software Engineering incorporates continuous assessment as additional modality that the students can use to pass it. The teaching team sets out a series of indicators based on numerical counts stemming from the results of the examination session on January, highlighting:

- Total students who pass on continuous assessment.

- Total students who fail on continuous assessment.

- Total students who pass on official assessment.

- Total students who fail on official assessment.

There's no doubt, the large number of students enrolled, guarantee the reliability of the results. Fig. 1 provides a chart showing the evolution of these indicators over the last three years:

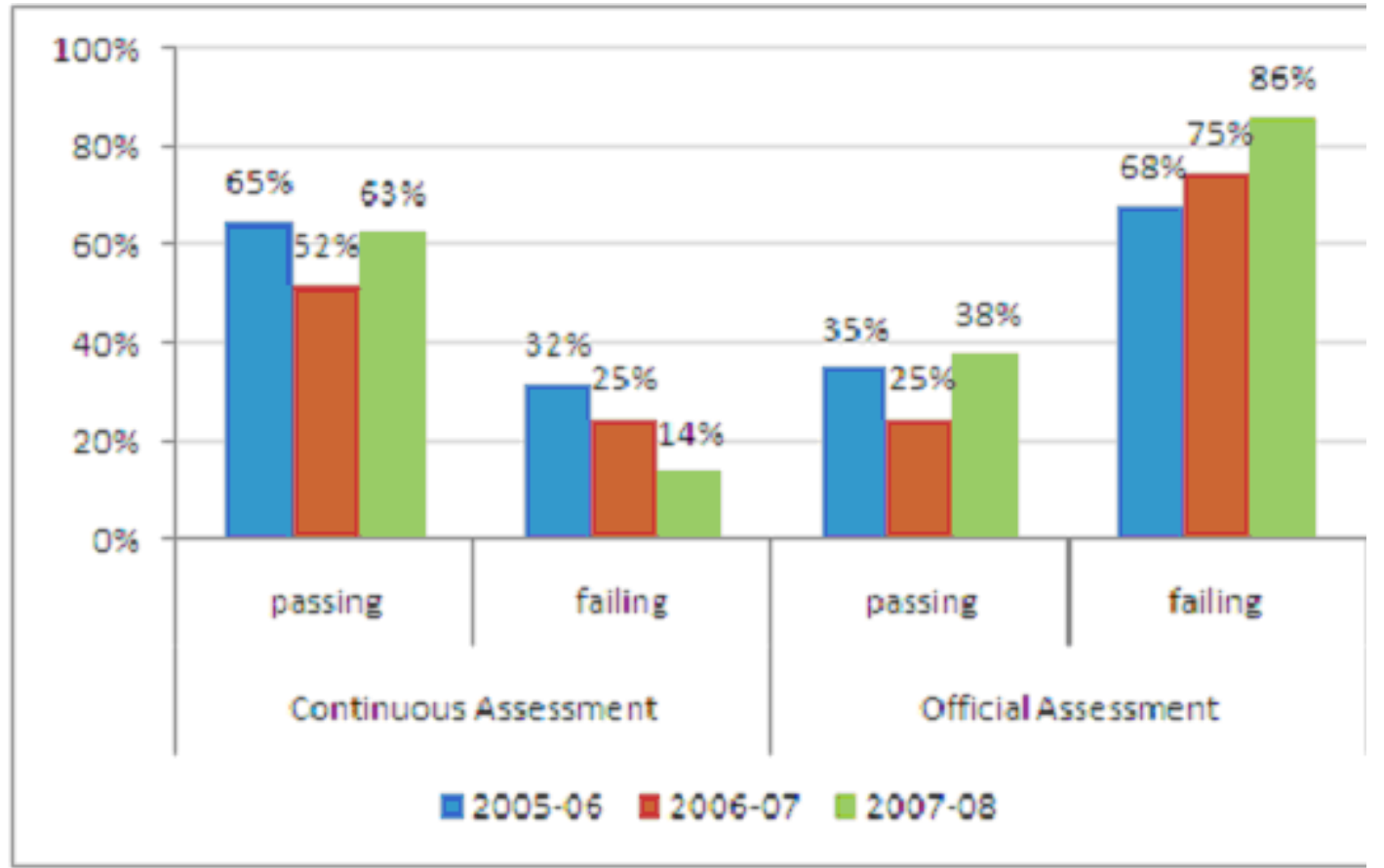

Fig. 1. Evolution results of the continuous and official assessment

If we look in detail the figure we can detect that: 
- The percentage of students who pass the subject in the form of continuous assessment is considerably higher, in all years, the percentage of the official. The average percentage of passing at the three academic years is doubled, $60 \%$ on continuous assessment compared to $33 \%$ of the official.

- Regarding to the failing the situation is completely inverted. In this case, the percentages of students who fail in continuous assessment are much lower than those of the official. Emphasize the academic year 2007-08, in which the proportion of failing in continuous assessment is $14 \%$ while in the official reaches $86 \%$.

As discussed above, if the student does not pass the subject in the form of continuous assessment, may still be submitted to the official assessment. In order to see the level of incidence of continuous assessment in the official assessment will take further annotations on the following indicators:

- Total students who fail the subject in the form of continuous assessment but they pass by official evaluation.

- Total students who pass the subject exclusively by the official evaluation.

According to the results obtained, we can conclude that the process of continuous assessment is presented as an additional advantage by offering greater guarantees to finally pass the subject [3].

Among the advantages that also get the student, we consider the following:

- Gradual assimilation of the contents subject and progressive development of the established powers.

- Knowledge about the teacher assessment, and the degree of demand required to pass.

- Information on the pace of learning needed to assimilate the contents and put them into practice through various workshops scheduled during the course, as well as in practice mandatory.

- Preparing to face successfully the final test according to the official assessment of the subject.

From the teacher point of view, the evaluation system provides continuous on-line information about subject that can contribute to improving or even redirect the process of student learning. However, the effort and workload of teachers are increased significantly, worthy of being valued and taken into account in case of wanting implants. Similarly, excessive care must be taken in several subjects that do not coincide with this evaluation system in the same period school because they can get to saturate the student.

\section{Acknowledgments}

We want to thank members of the Group of Research in Interaction and eLearning of the University of Salamanca for their collaboration in the form of critical feedback in the development of this article. This work is partially supported by Spanish Ministry of Education and Science through the research project KEOPS (TSI2005-00960) and by the Regional Ministry of Education of Junta de Castilla y León through the project SA056A07 


\section{References}

1. European Ministers of Education, The European Higher Education Area-Bologna Declaration, Bologna on the 19th of June 1999.

2. García, F.J. and Moreno, M.N. 2004. Software Modelling Techniques for a First Course in Software Engineering: A Workshop-Based Approach. IEEE Transactions on Education, Vol. 47, No. 2, May 2004.

3. González-Rosende, M.E. 2008. La Evaluación Continua en el Espacio Europeo de Educación Superior. 